\title{
Interpersonal Meaning-making in War Time Posters by A Multimodal Analysis
}

\author{
Qinqin Yang ${ }^{1}$ \\ ${ }^{1}$ School of Basic Science, Guangzhou Medical University, Guangzhou 510182, China
}

\begin{abstract}
Multimodality has become an exciting frontier of research. In this study, I deploy the Appraisal theory of discourse semantics within systemic-functional linguistics and the social semiotic approach of multimodal discourse analysis on images and texts to analyze the interpersonal meaning-making of posters from the US during World War II. It is found that images and verbiages of the multimodal texts of posters co-work in the process of naturalization and realizations of the interpersonal control of the potential viewers. Such an analysis will arouse the awareness of how interpersonal meaning is construed in the viewers and the poster designers.
\end{abstract}

Keywords: Interpersonal meaningmaking; Visual grammar; Appraisal theory; War time posters

\section{Introduction}

Posters can reflect the characteristics of a society at a specific period of time. So it has become a promising field for discourse analysis these years. The investigation of the interplay of multimodal semiotics has been a focus of recent researches in discourse analysis in western countries, which is called multimodal discourse analysis. Among the many theories developed in multimodal discourse analysis, one of the most important and fundamental theoretical frameworks is visual grammar by Kress and van Leeu- veen. Posters, as a special genre, also codeploy a multiplicity of semiotic modes (pictures and verbiage) to fulfill their communicative purpose. This study intends to explore both the text and visual features of posters from the interactive dimension. Based on the theory of Halliday [1,2], Martin [3-5], Kress and van Leeuwen [6,7], this study incorporates the Appraisal theory by Martin with the interactive function from visual grammar to analyze the interactive meaning-making by the images and verbiage and the image-verbiage relationship in posters. The present research is a response to the recognition of the role of visual literacy within the global context, as people 'live in one of the most artificial visual and image-saturated cultures in human history which makes understanding the complex construction and multiple social functions of visual imagery more important than ever before' [8]. This study offers a way of exploring posters from a linguistic perspective. In the mean time, it will also provide insight into Multimodal Discourse Analysis and the Appraisal theory, to better meet the opportunities and rise to the challenges brought by globalization.

The aim of this study is to contribute to the elaboration of multimodality and to carry out an analysis on the multimodal texts of posters created during the Second World War in the US. In that special era when other kinds of media was not as developed as today, how do posters work as powerful weapons to persuade and naturalize the public? By exploring the strategies exerting in these posters, it is ex- 
pected to offer us an insightful way to read these posters.

\section{Results}

I shall start the exploration of interactive meaning-making in terms of contact, social distance, and perspective. Engagement devices such as dialogue balloon and highlight will also be introduced, followed by modality both in images and verbiage. After the interactive exploring on image and verbiage, I shall analyze the cumulative evaluative aspects, namely, attitudinal meaning accumulated in the intersemiosis in terms of appraisal. Image-verbiage relationship will be examined at last.

\subsection{Contact}

Contact deals with the imaginary relation established between what is represented in the image and the viewers. Two choices are given in order to make a distinction: the represented participants either demand attention of the viewer, or they offer information. The 'demand' image typically features a human or quasi-human participant who gazes directly at the viewer, which creates a vector between the eye-line or gestures (if any) of the represented and interactive participants, demanding an answer from the viewers. While for 'offer' on the other hand, the represented participants (if human) do not look directly at the viewer but gaze away. Here, no direct contact is made, the represented participants are offered as objects for the viewer's contemplation.

The first poster (Figure 1) under discussion was one deeply loved by the public in the US. The represented character named Roise, quite famous at that time. It was the works of the American wellknown illustrator Norman Percevel Rockwell. Different from other women depicted as housewives or passive sup- porters of the war who were being forced to, in his works, Roise, wearing the same kind of dungaree as men labors did, was raising her arm up, showing the viewers her firm muscle. Thus Roise became a woman image full of vigor that was not afraid of challenge thrown upon her by the war. In this poster, she looked at the viewers firmly and persistently, forming an eye-line which connects her with the potential viewers, that's to say, contact is established to bring an imaginary relation between her and the potential viewers, as a result, a 'demand' status was set up. The author, in the voice of Roise, tried to seek recognition in the potential viewers women like Roise at the war time, and demand the same kind of vitality and courage from them, calling for their passionate participation in the production at home. Only by this way could they support the war and the country through the disaster at a time badly in need of labors when all the capable men had joined the army fighting in the front.

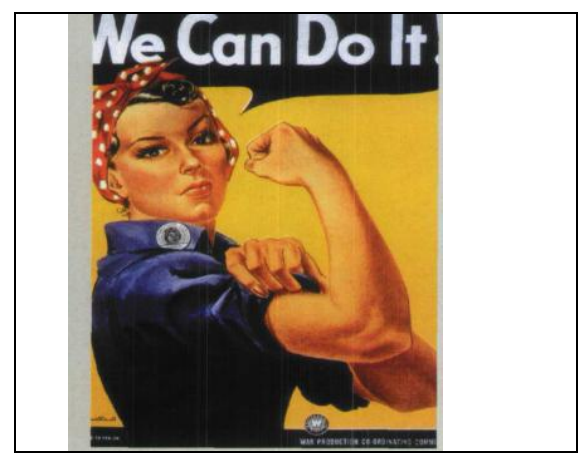

Fig. 1: The first poster.

\subsection{Social distance}

The second dimension of visual interaction is social distance, which is concerned with how images depict the represented participants as close to or far away from the viewer. Corresponding to images, Kress and van Leeuwen see formality of 'style' as the linguistic realization of so- 
cial distance. They classified three types of style: personal style is the "language of intimates". This style tends to implicitness, context-dependence and local frames of reference; it is the language of social solidarity in a world where much can be taken for granted. Social style is the language in which the outside business of the day is conducted. There are fewer colloquialisms and abbreviated forms here and greater use of standard syntax and lexis in this style. Greater explicitness is required because of the greater social distance between interactants. Finally, the 'public style' is the language of formal occasions, where people 'talk like books'. This is far more selfconscious than other styles, more explicit, more articulated in its use of full forms. In the public domain, interactants are maximally distant from one another [9].

In the poster (Figure 2), president Roosevelt's portrait was hanging over, taking more than half of the whole frame, as if god or the prophet showing his presence over head on the near sky. Here the author adopted the close personal distance which the close-up shot makes available to the viewer. The imaginary relation between the represented participant 'the president' and the viewer is made, which allows the viewer to imaginarily come as close to this public figure as if he were viewer-friendly, calling up a intimacy with him. The 'he' is looking directly at the viewers with a kind and peaceful smile on his face, the 'demand' status cooperate with the personal distance reinforced once again his closeness with the viewers. Underneath, five members of a family were standing together looking up and worshiping the president, with their backs faced the viewers. Here they were depicted from long shot, an impersonal way or social distance was established with the viewers. Meanwhile the vulnerable back view offered them to the viewers as objectified, as things for contemplation.
By this depiction the author intends 'them' to be the unfamiliar and strangers to us just as the most ordinary family we meet in the street. It made this impression to the potential viewers 'us' that every family was in the same grief just as we do, that is, all the American was mourning for the president. The president was still there guiding the people towards the future for he will always live in the heart of the American people.

In addition, this kind of guidance was reinforced by the high-angle shot of the president and eye-line-shot of the family from the vertical dimension. Shot from above means the president's power over the family which was shot from eye-line. This creates an imaginary idol or role model and fans relationship between them. For the viewers are identified as relative equal as the family in the poster, therefore they are also positioned as the worshiper of the president.

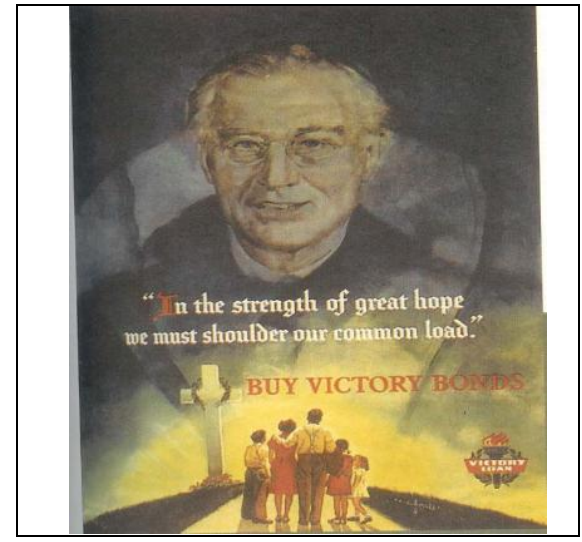

Fig. 2: The second poster.

\subsection{Sample analysis of a full poster}

In this section a comprehensive analysis will be devoted to a poster. That is, I shall analyze the poster from the interaction dimension of contact, social distance, and point of view (perspective); engagement devices and modality; then on attitudinal 
meaning accumulation. Image-verbiage relations will also be explored.

Analysis of the image part:

The poster (Figure 3) depicts a warm and delightful life scene of an ordinary American family - the whole family is welcoming the son, who has just come back from the front (holding baggage in his hand). The mother is so excited that she opens her arms and couldn't wait to embrace her dear son. The father also goes out of the door with pleasantly surprise on his face. The younger siblings are yelling at and running wildly towards their brother, all the other members of the family are looking at the son with their faces alight with ecstasy. It is noteworthy that right on the left of the poster around the corner a bashful girl is gazing deeply at the soldier, who could be his girl. A happy prosody is saturated in the whole image.

In terms of social distance, the image is taken at the public distance from which the viewers can at least see four or five figures with their surrounding environment. In this treatment of the distance, the author presents the viewer a happy and harmonious family, which the viewers will naturally identify with. As for point of view (perspective), the poster adopts an eye level, frontal angle, which implies a high level of involvement and presents the represented participants as part of the viewer's world. However, the back view of the soldier positions him in a vulnerable position, which presents the solder as the beloved son of every American family or the devoted solder who fight for the peace and happiness of every family. By the back view the viewers are also positioned in the same view with the solder in seeing and receiving the hearty welcome from the whole family.

There is no engagement devices deployed in this poster. The author's voice appears directly in the poster. The title of 'hasten the Homecoming' is well illus- trated by the image. And the unmarked imperative sentence 'buy victory bond' works as a 'bare assertion' of the author, and it puts the viewers into the position of obeying. The viewers are asked to buy victory bond in order to support the war. Thereby millions of American families can be reunited as soon as possible.

In terms of modality, due to its naturalistic method of the image, it possesses high modality value in color saturation and differentiation, contextualization and representation, depth, illumination and brightness. As for color modulation, this image applies relatively flat and less modulated color for the depiction of the skin and countenance of the represented participants.

After exploring the interactive meaning-making in this poster, now I shall turn to the evaluative part of the image. Inscribed positive affect of happiness is prevailing in this poster by their big smile on the faces and all kinds of welcome gestures. By the back view of the son, it can be argued that a positive judgement of social esteem is invoked in the potential viewers. In addition, the harmonious and happy scene of the family also arouses the positive appreciation of composition.

Analysis on the verbal part:

The title: Hasten [judgement: $t+$ propriety] the homecoming [affect: $\mathrm{t}+$ happiness] (Home means happiness and safety, especially in the war time where outside is turbulent home becomes more attracting for everyone. Thus homecoming is definitely a happy feeling.)

Taking into account both the verbal text and visual image in this poster, it can be found that a strong cohesive bond in attitudinal meaning is established between these two semiotic modes. The word 'hasten' invokes a positive evaluation which justify the image, the image on the other hand illustrates the ideational meaning while reinforcing the positive 
affect encoded in the verbal text of 'homecoming'. According to [10], this is how the 'multiplying meaning' happens.

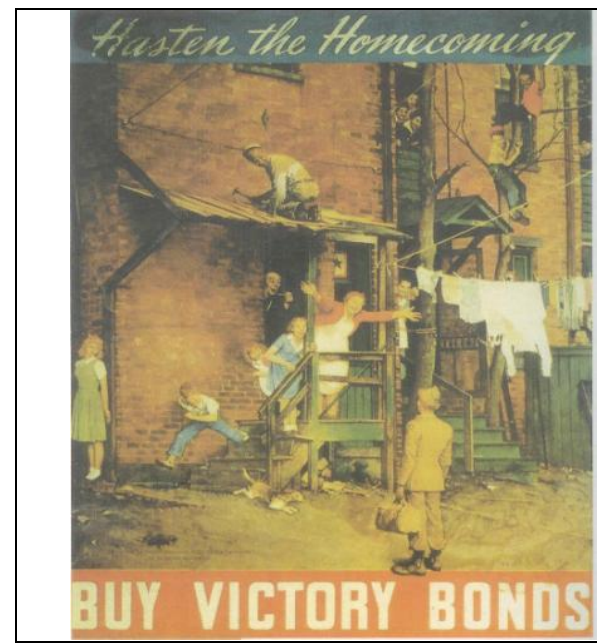

Fig. 3: The third poster.

\section{Conclusions}

I've made a detailed analysis on war time posters by examining the image and verbiage from the interpersonal meaningmaking dimension. The analysis is performed along the line of interaction, modality and evaluation. It is argued that besides the social relation of contact, social distance and perspective, engagement devices are also useful tools for interactive meaning-making. In addition, attitudinal meaning can also be accumulated in the images.

Through the analysis it demonstrates to us how the social relationship between the participants of the images is constructed, the communicative purpose of image designer, and the degree to which the viewers are involved with the image.

\section{References}

[1] Halliday, M.A.K, "An Introduction to Functional Grammar (2nd edition), " London: Arnold, 1994.

[2] Halliday, M.A.K, "Language as Social Semiotic: The Social Interpretation of Language and Meaning," London: Arnold/ Beijing: Foreign Language Teaching and Research Press, 1978/2001.

[3] Martin, J.R, "Beyond exchange: Appraisal systems in English. In Hunston, S. and Thompson, G (eds.) Evaluation in Text: Authorial Stance and the Construction of Discourse," Oxford: Oxford University Press, 2000.

[4] Martin, J.R. and White, P.R.R, “The language of Evaluation: Appraisal in English," London: Palgrave, 2005.

[5] Martin, J.R. and Rose, D, "Working with Discourse: Meaning beyond the Clause (2nd edition), " London: Continuum, 2007.

[6] Kress and van Leeuwen, T, "Reading Image: The Grammar of Visual Design," London: Routledge, 1996.

[7] Kress and van Leeuwen, T, "Reading Image: The Grammar of Visual Design(2nd edition), " London: Routledge, 2006.

[8] Kellner, D, "Critical perspectives on visual imagery in media and cyberculture, " On U.C.L.A Homepage: http://www.gseis.ucla.edu/faculty/kell ner/kellner.html.

[9] Macken-Horarik, M, "Interacting with the multimodal text: reflections on image and verbiage in ArtExpress, "Visual Communication, Vol. 3 (1): 5-26, 2004.

[10] Lemke, J.L, "Multiplying meaning: Visual and verbal semiotics in scientific text. In Martin, J.R. and Veel, R. (eds) Reading Science: Critical and Functional Perspective on Discourse of Science," London: Routledge, 1998. 